ENCYCLOPEDDIE Encyclopédie berbère

BERBERE

3 | 1986

3 | Ahaggar - Alī ben Ghaniya

\title{
Akrech (oued)
}

G. Souville

\section{OpenEdition}

Journals

Édition électronique

URL : http://journals.openedition.org/encyclopedieberbere/2403

DOI : 10.4000/encyclopedieberbere.2403

ISSN : 2262-7197

\section{Éditeur}

Peeters Publishers

\section{Édition imprimée}

Date de publication : 1 juillet 1986

Pagination : 426

ISBN : 2-85744-260-2

ISSN : 1015-7344

\section{Référence électronique}

G. Souville, "Akrech (oued) », Encyclopédie berbère [En ligne], 3| 1986, document A149, mis en ligne le 01 décembre 2012, consulté le 12 octobre 2020. URL : http://journals.openedition.org/ encyclopedieberbere/2403; DOI : https://doi.org/10.4000/encyclopedieberbere.2403

Ce document a été généré automatiquement le 12 octobre 2020

(c) Tous droits réservés 


\section{Akrech (oued)}

\section{G. Souville}

1 En 1946, une hache plate en métal fut découverte aux environs de Rabat, sur la route des Zaërs (carte du Maroc au 50 000e, Temara, c.L. env. 367,8 × 376,8) ; elle a été trouvée fortuitement et à fleur de terre. Elle est en forme de trapèze allongé (L. 15,5 cm; 1 . au tranchant 4,6 ; 1 . au talon 1,7 ; ép. max. $0,6 \mathrm{~cm}$; poids $195,5 \mathrm{~g})$. Le tranchant usé, légèrement ébréché, devait être faiblement incurvé.

Le métal brut de fonderie, au grain assez fin, a conservé une jolie patine brillante. Des oxydations superficielles lui donnent un aspect grenelé; des concrétions venant sans doute du séjour en terre, couvrent une partie de la surface.

Une analyse chimique puis deux analyses spectrographiques, la dernière effectuée en 1963 au Laboratoire d'Anthropologie préhistorique de la Faculté des Sciences de Rennes a montré qu'il s'agissait d'un bronze, à assez forte proportion d'étain; de nombreuses impuretés indiquent que le cuivre a été tiré d'un minerai de surface, du genre des cuivres gris :

$\mathrm{Sn} \mathrm{Pb} \mathrm{Sb}$ As Fe Mn Ni Bi Zn Ag Si

$10 \%$ 0,13\% 0,092\% 0,225 \% 0,059\% 0,001 \% 0,020\% 0,005\% 0 0,2\% traces

4 Par sa forme, cette hache s'apparente à celles de la civilisation argarique. Il s'agit d'un des rares objets en bronze trouvés en Afrique du Nord (cf CAMPS G., Aux origines de la Berbérie. Monuments et rites funéraires protohistoriques, Paris, 1961, p. 419-457). Ici la proportion d'étain est très supérieure à celle de la hache de Tiaret (CADENAT P., Découverte d'une hache de bronze dans la commune mixte de Tiaret, Libyca, t. 4, 1956, p. 283-287) et rappellerait plutôt celle de certains objets de Roknia ou de Bou Nouara. Elle est un des éléments qui permettent de reconnaître un âge du Bronze au Maroc (souvilLE G., Recherches sur l'existence d'un âge du Bronze au Maroc, Atti VI Congr. intern. Sci. preist. le protost., Rome, 1962, t. 2 (1965), p. 419-424). 


\section{BIBLIOGRAPHIE}

GIOT P. R. et SOUVILLE G. La hache en bronze de l'oued Akrech (Maroc), Libyca, t. 12, 1964, p. 301-306, 3 fig.

SOUVILlE G. Atlas préhistorique du Maroc, 1, Le Maroc atlantique. Paris, 1973, p. 96-98, fig. 38.

INDEX

Mots-clés : Maroc, Protohistoire 